\title{
Pengembangan Asesmen Formatif pada Materi Sistem Sirkulasi untuk Mengukur Kemampuan Berpikir Kritis Siswa Kelas XI SMA Laboratorium UM
}

\section{Developing Formative Assessment Instruments to Measure Students' Critical Thinking Ability in Human Circulatory System Material for $11^{\text {th }}$ Grade Students of UM High School Laboratorium}

\author{
Ahmad Kamal Sudrajat, Murni Saptasari \& Amy Tenzer \\ Universitas Negeri Malang, Malang, Jawa Timur, Indonesia \\ email: kamalsudrajat2@gmail.com
}

\begin{abstract}
Abstrak
Penelitian ini bertujuan untuk mengembangkan asesmen formatif yang dapat mengukur kemampuan berpikir kritis siswa pada materi system sirkulasi dan menguji validitas, kepraktisan, dan keefektifan produk asesmen formatif yang dikembangkan. Produk dikembangkan dengan model pengembangan $A D D I E$. Produk yang dikembangkan berupa instrumen observasi diskusi kelas, instrumen observasi kegiatan praktikum, dan soal tes kognitif. Kesimpulan penelitian ini adalah asesmen formatif yang dikembangkan layak, praktis, dan efektif digunakan dan dapat mengukur serta melatih kemampuan berpikir kritis ssiwa.
\end{abstract}

Kata kunci: asesmen formatif, kemampuan berpikir kritis, sistem sirkulasi

\begin{abstract}
The purpose of the study is to develop a formative assessment that can measure students' critical thinking skills on the circulatory system and test the validity, efficacy, and effectiveness of developed formative assessment products. Products developed with the ADDIE development model. The product developed in the form of observation instrument of class discussion, observation instrument of practicum activity, and test of cognitive test. The conclusions of this study are formative assessments that are developed feasible, practical, and effective use and can measure and train critical thinking skills of the students.
\end{abstract}

Keyword: critical thinking skills, circulatory system, formative assessment

\section{PENDAHULUAN}

Kemampuan berpikir kritis merupakan kemampuan berpikir siswa yang sangat penting untuk dikembangkan di sekolah. Kemampuan berpikir kritis sangat penting dikembangkan agar Indonesia dapat bersaing secara global di abad ke 21. Menurut Indahri (2009) ada empat kompetensi yang harus dimiliki siswa agar dapat bersaing di abad 21, yaitu critical thinking and problem solving (berpikir kritis dan menyelesaikan masalah), creativity (kreatifitas), communication skills (kemampuan berkomunikasi), dan ability to work collaboratively (kemampuan untuk bekerja sama). Setiap siswa memiliki potensi untuk berpikir kritis tetapi permasalahan yang ada adalah bagaimana cara mengembangkan kemampuan tersebut di dalam proses pembelajaran.

Pembelajaran sebagai suatu proses mengandung tiga unsur yang memiliki hubungan timbal balik, yakni tujuan pembelajaran, proses pembelajaran, dan penilaian (asesmen) pembelajaran (Sudjana, 2017). Asesmen pembelajaran yang merupakan salah satu unsur dalam pembelajaran digunakan untuk mengetahui sejauhmana ketercapaian kompetensi 
siswa dan keefektifan proses pembelajaran yang dilakukan untuk mencapai tujuan pembelajaran. Asesmen merupakan bagian yang tidak terpisahkan dari proses pembelajaran. Asesmen pembelajaran penting dilakukan agar siswa mengetahui apa yang telah mereka pelajari atau menunjukkan apa yang belum mereka pelajari (Jabbarifar, 2009). Menurut Wiliam (2013)asesmen penting dilakukan untuk 1) mengklarifikasi, berbagi, dan memahami tujuan pembelajaran, 2) melakukan diskusi, pembelajaran yang efektif dan menghasilkan bukti pembelajaran, 3) memperoleh umpan balik agar pembelajaran lebih baik, 4) mengaktifkan siswa sebagai sumber belajar satu sama lain, dan 5) mengaktifkan siswa sebagai pemilik pembelajaran mereka sendiri.

Berdasarkan hasil observasi di SMA Laboratorium UM yang dilakukan selama KPL pada bulan September sampai dengan Oktober 2017 pada materi pembelajaran sel diperoleh hasil bahwa untuk menilai kemampuan siswa, guru hanya menggunakan paper and pencil test dan tes lisan. Pantiwati (2011)mengatakan, paper and pencil test saja tidak memberikan siswa kesempatan untuk mengembangkan penalarannya, selain itu juga mempersempit guru untuk berinovasi dalam proses pembelajaran. Pelaksanaan penilaian di sekolah harus mencakup berbagai jenis alat ukur yang dapat mengukur aspek pengetahuan, aspek sosial, dan aspek keterampilan. Hal ini disebabkan semua alat ukur memiliki peranan tersendiri dan saling mendukung dalam pengukuran hasil belajar. Berdasarkan hasil observasi jenis soal yang digunakan untuk mengukur aspek pengetahuan siswa berupa soal $\mathrm{C} 1$ dan $\mathrm{C} 2$, hal ini belum bisa melatih kemampuan berpikir kritis siswa.

Apabila ditinjau kembali Kompetensi Dasar yang harus dicapai pada materi pokok sistem sirkulasi, yaitu KD 3.6 "Menganalisis hubungan antara struktur jaringan penyusun organ pada sistem sirkulasi dalam kaitannya dengan bioproses dan gangguan fungsi yang dapat terjadi pada sistem sirkulasi manusia", maka instrumen soal yang diberikan guru kepada siswa belum sesuai dengan Kompetensi Dasar yang harus dicapai. Model pembelajaran yang digunakan oleh guru adalah inkuiri terbimbing, hal ini sudah sesuai dengan hasil penelitian yang dilakukan oleh Hermayani, Dwiastuti, \& Marjono (2015) yang menyatakan bahwa model pembelajaran inkuiri terbimbing dapat meningkatkan kemampuan berpikir kritis siswa. Menurut guru mata pelajaran biologi kelas XI, materi pembelajaran yang sulit disusun asesmen formatif adalah sistem sirkulasi.Berdasarkan latar belakang yang telah diuraikan di atas, perlu dikembangkan suatu asesmen formatif yang didalamnya terdapat indikator kemampuan berpikir kritis dan dapat mengukur kemampuan siswa yang meliputi aspek pengetahuan, sikap, dan keterampilan. Asesmen formatif yang dikembangkan diharapkan dapat digunakan untuk mengukur dan melatih kemampuan berpikir kritis siswa.

\section{METODE PENELITIAN}

Penelitian ini menggunakan model pengembangan ADDIE menurut Branch (2009). Subjek penelitian ini adalah siswa SMA Laboratorium UM program konsentrasi MIPA tahun ajaran 2017/2018 
kelas XI sebanyak 3 kelas yang berjumlah 101 siswa. Waktu penelitian selama bulan November 2017. Jenis data dalam penelitian ini adalah data kuantitatif dan kualitatif. Instrumen yang digunakan dalam penelitian ini adalahlembar validasi instrumen asesmen formatif, lembar angket respon pengguna, lembar observasi kegiatan diskusi kelas, lembar observasi kegiatan praktikum, dan tes formatif dalam bentuk pilihan ganda jawaban tunggal, pilihan ganda sebab akibat, dan uraian. Teknik analisis yang digunakan adalah teknik analisis isi, teknik analisis kualitatif, dan analisis butir soal.

\section{HASIL DAN PEMBAHASAN}

\subsection{Hasil}

Data hasil uji coba produk berupa data hasil validasi produk (lembar validasi ahli asesmenpadatabel 1, lembar validasi ahli materipadatabel 2, lembar validasi praktisi lapangan pada tabel 3), data hasil uji coba produk (hasil observasi diskusi kelas pada tabel 4 dan 5, hasil observasi kegiatan praktikum pada tabel 6 dan 7, dan analisis butir soal), data uji kepraktisan produk (hasil angket respon pengguna), dan data uji keefektifan produk (hasil tes kognitif siswa pada tabel 10).

Tabel 1. Hasil Validasi Ahli Asesmen

\begin{tabular}{|c|c|c|c|}
\hline No & Asesmen yang dikembangkan & $\begin{array}{l}\text { Rerata } \\
\text { Skor }\end{array}$ & Saran dan Komentar \\
\hline 1 & Asesmen diskusi kelas & 3,6 & $\begin{array}{l}\text { - Perlu adanya petunjuk diskusi kelas } \\
\text { - Perlu penambahan aspek kebenaran materi } \\
\text { - Perlu memilih salah satu aspek diskusi kelas }\end{array}$ \\
\hline 2 & Asesmen kegiatan praktikum & 3,7 & - Perlu adanya petunjuk praktikum \\
\hline 3 & Asesmen pengetahuan & 3,9 & $\begin{array}{l}\text { - Perlu adanya kunci jawaban } \\
\text { - Perlu adanya perbaikan soal nomor } 1 \text { dan } 5 \text { karena } \\
\text { termasuk C3 }\end{array}$ \\
\hline
\end{tabular}

Skala $1-4$

Tabel 2. Hasil Validasi Ahli Materi

\begin{tabular}{|c|c|c|}
\hline Asesmen yang dikembangkan & Rerata Skor & Saran dan Komentar \\
\hline $\begin{array}{l}\text { Asesmen pengetahuan (soal tes } \\
\text { kognitif) }\end{array}$ & 3,8 & $\begin{array}{c}\text { - Soal layak digunakan sebagai instrumen } \\
\text { evaluasi }\end{array}$ \\
\hline
\end{tabular}

Tabel 3. Hasil Validasi Praktisi Lapangan

\begin{tabular}{clcl}
\hline No & \multicolumn{1}{c}{$\begin{array}{c}\text { Asesmen yang } \\
\text { dikembangkan }\end{array}$} & $\begin{array}{c}\text { Rerata } \\
\text { Skor }\end{array}$ & \multicolumn{1}{c}{ Saran dan Komentar } \\
\hline 1 & Asesmen diskusi kelas & 3,8 & - \\
2 & $\begin{array}{l}\text { Asesmen kegiatan } \\
\text { praktikum }\end{array}$ & 3,6 & - \\
3 & Asesmen pengetahuan & 3,7 & $\begin{array}{l}\text { - Perlu adanya perbaikan soal nomor 1, 5, 7, 11 } \\
\text { Soal yang kurang mengarah ke pengembangan kemampuan } \\
\text { berpikir kritis perlu disempurnakan }\end{array}$ \\
\hline
\end{tabular}

Skala $1-4$ 
Tabel 4. Hasil Observasi Diskusi Kelas

\begin{tabular}{clcccc}
\hline Rerata & \multirow{2}{*}{ Kriteria } & XI MIPA 1 & XI MIPA 2 & XI MIPA 3 & Rerata \\
\cline { 3 - 5 } Skor & & $\Sigma$ Siswa & $\Sigma$ Siswa & $\Sigma$ Siswa & Persentase \\
\hline$x>3,4$ & Sangat Baik & 7 & 16 & 12 & 34,6 \\
$2,8<x \leq 3,4$ & Baik & 17 & 14 & 17 & 47,6 \\
$2,2<x \leq 2,8$ & Cukup Baik & 9 & 4 & 4 & 16,8 \\
$1,6<x \leq 2,2$ & Kurang Baik & 1 & 0 & 0 & 1 \\
$x \leq 1,6$ & Sangat Kurang & 0 & 0 & 0 & 0 \\
\hline
\end{tabular}

Tabel 5. Rerata Aktivitas Siswa dalam Diskusi Kelas pada Tiap Aspek

\begin{tabular}{clcccc}
\hline \multirow{2}{*}{ No } & \multirow{2}{*}{ Aspek yang diamati } & \multicolumn{3}{c}{ Rerata tiap aspek } & \multirow{2}{*}{ Rerata } \\
\cline { 3 - 5 } & & XI MIPA 1 & XI MIPA 2 & XI MIPA 3 & \\
\hline 1 & Kemampuan bertanya & 3,1 & 3,1 & 2,8 & 3,0 \\
2 & Kemampuanmenjawab & 3,2 & 3,2 & 3,4 & 3,3 \\
3 & Kemampuanmenjelaskan & 2,9 & 2,9 & 2,7 & 2,8 \\
4 & Kemampuanmengahargai orang lain & 3,7 & 3,7 & 3,8 & 3,7 \\
\hline
\end{tabular}

Skala $1-4$

Tabel 6. Hasil Observasi Kegiatan Praktikum

\begin{tabular}{cccccc}
\hline Rerata & \multirow{2}{*}{ Kriteria } & XI MIPA 1 & XI MIPA 2 & XI MIPA 3 & Rerata \\
\cline { 3 - 5 } Skor & & $\Sigma$ Siswa & $\Sigma$ Siswa & $\Sigma$ Siswa & Persentase \\
\hline$x>3,4$ & Sangat Terampil & 17 & 20 & 21 & 63,6 \\
$2,8<x \leq 3,4$ & Terampil & 17 & 14 & 12 & 36,4 \\
$2,2<x \leq 2,8$ & Cukup Terampil & 0 & 0 & 0 & 0 \\
$1,6<x \leq 2,2$ & Kurang Terampil & 0 & 0 & 0 & 0 \\
$x \leq 1,6$ & Sangat Kurang Terampil & 0 & 0 & 0 & 0 \\
\hline
\end{tabular}

Tabel 7. Rerata Aktivitas Siswa dalam Kegiatan Praktikum pada Tiap Aspek

\begin{tabular}{|c|c|c|c|c|c|}
\hline \multirow{2}{*}{ No } & \multirow{2}{*}{ Aspek yang diamati } & \multicolumn{3}{|c|}{ Rerata tiap aspek } & \multirow{2}{*}{ Rerata } \\
\hline & & XI MIPA 1 & XI MIPA 2 & XI MIPA 3 & \\
\hline 1 & Melakukan percobaan sesuai dengan prosedur & 3,4 & 3,8 & 3,6 & 3,7 \\
\hline 2 & Keterampilan menggunakan alat & 3,8 & 3,8 & 3,4 & 3,8 \\
\hline 3 & Membuatkesimpulan & 3,3 & 3,2 & 3,4 & 3,2 \\
\hline
\end{tabular}

Skala $1-4$

Tabel 8. Hasil Analisis Butir Soal

\begin{tabular}{ccccc}
\hline Tipe Soal & Nomor Soal & Tingkat Kesukaran & Realibilitas & Daya Beda \\
\hline \multirow{4}{*}{ Pilihan } & 1 & Mudah & & Cukup \\
Ganda & 2 & Mudah & & Cukup \\
& 3 & Sedang & Reliabel (Reliabilitas Tinggi) & Sangat Baik \\
& 5 & Sedang & & Baik \\
& 6 & Sedang & & Baik \\
& 1 & Sedang & Budah & Baik \\
\hline \multirow{5}{*}{ Soal Uraian } & 2 & Mudah & & Cukup \\
& 3 & Sedang & & Baik \\
& 4 & Sedang & & Rukup \\
& 5 & Sedang & & Baik \\
& 6 & Mudah & & Baik \\
& 7 & Sedang & & Cukup \\
\hline
\end{tabular}


Persentase soal dengan tingkat kesukaran mudah sebanyak 38,5\% dan sedang sebanyak $61,5 \%$. Persentase soal dengan daya beda cukup sebanyak $38,5 \%$, baik sebanyak 46,1 $\%$, dan sangat baik sebanyak $15,4 \%$.

Tabel 9. Hasil Lembar Respon Guru

\begin{tabular}{clcl}
\hline \multirow{2}{*}{ No } & Asesmen yang dikembangkan & Rerata & Saran dan Komentar \\
\hline 1 & Asesmen diskusi kelas & 3,7 & - \\
2 & Asesmen kegiatan praktikum & 3,9 & - \\
3 & Asesmen pengetahuan & 3,7 & - Secara keseluruhan soal yang diberikan kepada \\
& & & siswa sudah menunjukkan berpikir kritis \\
\hline
\end{tabular}

Skala $1-4$

Tabel 10. Hasil Tes Kognitif Siswa

\begin{tabular}{lcccccc}
\hline \multicolumn{1}{c}{ Variasi } & \multicolumn{2}{c}{ XI MIPA 1 } & \multicolumn{2}{c}{ XI MIPA 2 } & \multicolumn{2}{c}{ XI MIPA 3 } \\
\hline Jumlah siswa & \multicolumn{2}{c}{34} & \multicolumn{2}{c}{34} & \multicolumn{2}{c}{33} \\
\hline \multirow{2}{*}{ Rata - rata } & Skor & $\begin{array}{c}\text { Skor } \\
\text { Konversi }\end{array}$ & Skor & $\begin{array}{c}\text { Skor } \\
\text { Konversi }\end{array}$ & Skor & $\begin{array}{c}\text { Skor } \\
\text { Konversi }\end{array}$ \\
\cline { 2 - 8 } Skor tertingggi & 70,6 & 2,8 & 71,5 & 2,9 & 83,8 & 3,4 \\
Skor terendah & 92 & 3,7 & 88 & 3,5 & 96 & 3,8 \\
\hline
\end{tabular}

\subsection{Pembahasan}

Kemampuan berpikir kritis siswa perlu dikembangkan karena dapat membantu siswa dalam pembelajaran Biologi dan membuat siswa memiliki kecakapan hidup di Abad 21. Green stein (2012) menyatakan bahwa pembelajaran pada Abad 21 memiliki karakteristik 4C yaitu kemampuan komunikasi, kemampuan kolaborasi, kemampuan berpikir kritis dan kemampuan pemecahan masalah, dan kemampuan mencipta dan berinovasi. Berdasarkan hal tersebut kemampuan berpikir kritis perlu untuk dikembangkan. Sudjana (2017) menyatakan bahwa pembelajaran sebagai suatu proses mengandung tiga unsur yang memiliki hubungan timbal balik, yakni tujuan pembelajaran, proses pembelajaran, dan penilaian (asesmen) pembelajaran. Berdasarkan pendapat tersebut pengembangan asesmen pembelajaran penting dilakukan agar tujuan pembelajaran dapat tercapai. Asesmen yang baik dapat mengukur kemampuan berpikir kritis siswa sehingga kemampuan berpikir siswa dapat berkembang. Asesmen formatif dipilih karena asesmenformatif dapat membantu guru memperolehfeedback tentang proses pembelajaran(Saptono, Rustaman\& Widodo, 2013).

Tahap pengembangan (Develop) dilakukan untuk mengetahui validitas asesmen formatif yang dikembangkan. Menurut Sugiyono (2016), validitas instrumen yang dikembangkan dapat dikatakan valid apabila telah memenuhi construct validity (validitas konstruksi) dan content validity (validitas isi). Instrumen yang dikembangkan memenuhi validitas konstruksi jika instrumen tersebut dapatmengukur apa yang seharusnya diukur, sesuai dengan yang didefinisikan. Pengujian validitas konstruk dapat menggunakan pendapat atau penilaian dari pakar atau ahli (judgement experts), yang selanjutnya 
hasil tersebut dihitung dan dikonversikan sesuai dengan kriteria yang telah ditetapkan. Validitas konstruk dalam penelitian ini dilakukan oleh 3 validator yaitu validator ahli asesmen, validator ahli materi, dan validator praktisi lapangan. Hasil validasi dari validator menunjukkan instrumen asesmen formatif yang dibuat layak digunakan untuk tahap implementasi. Meskipun instrumen yang dikembangkan sudah dinyatakan sangat valid, namun tetap dilakukan revisi berdasarkan masukan dari validator.

Tahap implementasi dilaksanakan selama 2 pekan (4 kali pertemuan), dalam tahap implementasi digunakan model pembelajaran inkuiri terbimbing yang di dalamnya terdapat kegiatan diskusi kelas, praktikum dan ulangan harian. Tahap implementasi bertujuan untuk memperoleh data kepraktisan dan keefektifan produk asesmen formatif yang dikembangkan. Kegiatan diskusi di dalam sintaks inkuiri terbimbing termasuk dalam tahap mengumpulkan data dan menguji hipotesis. Kegiatan diskusi kelas bertujuan untuk melatih kemampuan berpikir kritis yang meliputi meminta dan menjawab penjelasan, melakukan deduksi, dan melakukan induksi. Implementasi instrumen kegiatan diskusi kelas menunjukkan hasil sebagian besar siswa memiliki kriteria baik dan sangat baik ketika melakukan diskusi berdasarkan aspek penilaian yang disusun (Tabel 4). Azizmalayeri, Mirshahjafari, Sharif, Asgari, \& Omidi (2012) mengatakan bahwa ada pengaruh yang signifikan antara inkuiri terbimbing dengan peningkatan kemampuan berpikir kritis siwa dan diskusi merupakan suatu hal yang perlu diperhatikan dalam model pembelajaran inkuiri terbimbing. Efendi
(2012) dalam penelitiannya menyatakan bahwa penerapan metode diskusi sangat baik dalam meningkatkan kemampuan bepikir kritis siswa. Stears \& Gopal (2010) menyatakan bahwa dengan adanya kegiatan presentasi sangat bermanfaat bagi siswa, yaitu melatih keberanian siswa untuk lebih aktif dalam berbicara di depan orang banyak, melatih kecepatan dan ketepatan dalam menjawab pertanyaan dan menerangkan/ mengemukakan sesuatu, dapat melatih diri menerima pendapat atau masukan dari orang lain, dan ilmu yang di persentasikan akan berkembang karena adanya proses tanya jawab. Kegiatan presentasi bertujuan untuk melatih kemampuan berpikir kritis berupa meminta dan mengklarifikasi jawaban.

Implementasi lembar observasi kegiatan praktikum dilaksanakan pada pertemuan ke 3, praktikum pada materi sistem sirkulasi berupa penghitungan denyut nadi pada saat istirahat dan setelah melakukan aktivitas. Kegiatan praktikum dalam model pembelajaran inkuiri terbimbing dilaksanakan pada tahap mengumpulkan data. Kegiatan praktikum bertujuan untuk melatih kemampuan berpikir kritis yang meliputi merumuskan masalah dan membuat keputusan. Hasil observasi dari pelaksanaan praktikum menunjukkan kinerja siswa secara umum terampil dan sangat terampil (Tabel 6). Hal ini sesuai dengan hasil penelitian dari Sholahuddin \& Suharto (2016) yang menyatakan bahwa pembelajaran yang menggunakan kegiatan praktikum menjadikan siswa terampil jika dilihat dari segi keterlibatan dan motivasi dalam pembelajaran di kelas maupun di laboratorium. Hal tersebut didukung oleh Zaini (2016) yang menyatakan bahwa 
kemampuan berpikir kritis siswa dapat berkembang karena siswa terbiasa diberi bahan konseptual, jika siswa tidak memiliki minat dalam proses pembelajaran maka proses berpikir kritis tidak akan dilakukan. Keterampilan siswa dalam melakukan praktikum dapat dilihat dari hasil analisis yang menunjukkan bahwa setiap aspek yang dinilai masuk dalam kategori baik dan sangat baik (Tabel 7).

Tahap evaluasi dilakukan untuk mengetahui kepraktisan dan kefektifan produk asesmen formatif yang dikembangkan. Kepraktisan produk asesmen formatif dilihat dari hasil respon pengguna (guru) dalam hal kemudahan untuk digunakan dan diadministrasikan. Berdasarkan hasil angket respon pengguna (Tabel 9), asesmen formatif yang dikembangkan berupa lembar observasi diskusi kelas, lembar observasi kegiatan praktikum, dan soal tes kognitif siswa termasuk dalam kategori sangat praktis untuk digunakan dalam proses pembelajaran. Hasil angket yang diberikan kepada guru ini juga didukung oleh hasil analisis butir soalpadatabel 8 yang menunjukkan bahwa soal tes kognitif yang diberikan kepada siswa masuk dalam kategori sedang atau mudah. Menurut hasil penelitian Sihaloho (2017), ada hubungan yang positif dan signifikan antara kemampuan berpikir kritis dengan hasil belajar siswa. Hasil penelitian tersebut menunjukkan jika kemampuan berpikir kritis siswa tinggi, maka siswa tersebut mudah dalam mengerjakan soal yang diberikan.

Keefektifan produk asesmen kegiatan diskusi kelas yang dikembangkan berdasarkan hasil penilaian selama kegiatan diskusi kelas. Berdasarkan hasil penilaian menunjukkan hasil sebagian besar siswa memiliki kriteria baik dan sangat baik ketika melakukan diskusi kelas. Keefektifan produk asesmen kegiatan praktikum yang dikembangkan berdasarkan hasil penlilaian selama kegiatan praktikum. Berdasarkan hasil penilaian menunjukkan hasil seluruh siswa memiliki kriteria terampil dan sangat terapil ketika melakukan diskusi kelas. Keefektifan produk asesmen tes kognitif yang dikembangkan diukur berdasarkan hasil tes kognitif siswa. Hasil tes kognitif siswa masuk dalam kategori baik. Berdasarkan hal tersebut soal tes kognitif yang dikembangkan efektif digunakan untuk mengukur kemampuan berpikir kritis. Hal ini dikarenakan didalam soal tes kognitif terdapat indikator kemampuan berpikir kritis. Rerata nilai yang diperoleh siswa masuk dalam kategori baik. Asesmen dapat digunakan untuk melatih kemampuan berpikir kritis dikarenakan siswa akan terbiasa untuk berpikir kritis. Hal ini sesuai dengan pernyataan Akbar et. al. (2016) yang menyatakan bahwa, asesmen tes kognitif yang mengandung indikator kemampuan berpikir kritis sangat penting untuk diterapkan di dalam kelas agar tidak hanya mengembangkan kompetensi siswa, tetapi juga kemampuan berpikir kritis mereka.

Hasil tes kognitif siswa tidak hanya ditentukan oleh kualitas instrumen asesmen yang digunakan, tetapi juga ditentukan oleh proses pembelajaran. Proses pembelajaran selama penelitian menggunakan model inkuiri terbimbing. Inkuiri terbimbing merupakan salah satu model pembelajaran yang sesuai untuk mengembangkan kemampuan berpikir kritis dan dianjurkan dalam kurikulum 
2013 karena inkuiri terbimbing merupakan model pembelajaran yang menggunakan metode ilmiah untuk menemukan suatu konsep melalui proses berpikir yang sistematis. Berdasarkan hasil penelitian Duran \& Dökme (2016), tingkat berpikir kritis siswa yang diajar menggunakan model pembelajaran inkuiri terbimbing lebih tinggi daripada siswa yang diajar menggunakan model pembelajaran tradisional. Hal ini menunjukkan bahwa penggunaan model pembelajaran inkuiri terbimbing efektif untuk meningkatkan kemampuan berpikir kritis siswa.

\section{SIMPULAN}

Telah dikembangkan asesmen formatif berupa instrumen observasi diskusi kelas, instrumen observasi kegiatan praktikum, dan soal tes kognitif (pilihan ganda jawaban tunggal, pilihan ganda sebab akibat, dan uraian). Keunggulan produk yang dihasilkan adalah (1) asesmen formatif yang dikembangkan berupa instrumen observasi diskusi kelas, instrumen observasi kegiatan praktikum, dan soal tes kognitif terdapat indikator kemampuan berpikir kritis, (2) asesmen formatif yang dikembangkan berupa instrumen observasi diskusi kelas, instrumen observasi kegiatan praktikum, dan soal tes kognitif layak, praktis, dan efektif digunakan dalam proses pembelajaran. Kelemahan produk yang dihasilkan antaralain (1) asesmen formatif yang dikembangkan belum dapat menilai siswa secara keseluruhan dikarenakan hanya 3 instrumen yang disusun yaitu Instrumen observasi diskusi kelas, observasi praktikum, dan instrumen soal tes kognitif (2) asesmen formatif yang dikembangkan harus menggunakan model pembelajaran yang sesuai misalnya Inkuiri, PjBL (Project Based Learning), PBL (Problem Based Learning), dan PS (Problem Solving). Saran untuk penelitian selanjutnya adalah (1) memperluas implementasi produk sehingga diperoleh data kepraktisan dan keefektifan produk yang lebih baik dan (2) melakukan eksperimenpengaruh penggunaan asesmen formatif yang dikembangkan terhadap kemampuan berpikir kritis siswa.

\section{DAFTAR RUJUKAN}

Akbar, A. A. N. M. \& Wijaya, R. A. (2016). Exploring the Use of One Meeting Theme-BasedExtended Response: A Practical Critical Thinking Assessment Tool for ClassroomPractices. Proceeding International Conference onEducational Research and Evaluation (ICERE) 2016. 20 - 24.

Azizmalayeri, K., Mirshahjafari, E., Sharif, M., Asgari, M., \& Omidi, M. (2012). The impact of guided inquiry methods of teaching on the critical thinking of high school students, 3(10).

Branch, R. M. (2009). Instructional Design: The ADDIE Approach. Boston, MA: Springer US. https://doi. org/10.1007/978-0-387-09506-6

Duran, M., \& Dökme, İ. (2016). The effect of the inquiry-based learning approach on student's critical-thinking skills. EURASIA Journal of Mathematics, Science and Technology Education, 12(12), 2887-2908. https://doi.org/10.12973/eurasia.2016.02311a

Greenstein, L. M. (2012). Assessing 21st Century Skills. Thousand Oaks, United States: SAGE Publications Inc.

Hermayani, A. Z., Dwiastuti, S., \& Marjono, M. (2015). Peningkatan Motivasi Belajar Dan Kemampuan Berpikir Kritis Siswa Pada Materi Ekosistem Melalui Penerapan Model Inkuiri Terbimbing.BIOEDUKASI (Jurnal Pendidikan Biologi), 6(2), 79 - 85. https://doi.org/10.24127/bioedukasi.v6i2.335

Indahri, Y. (2009). Kebijakan Lima Hari Sekolah. Info Singkat Kesejahteraan Sosial, IX(13), 9-12. Retrieved from 
www.puslit.dpr.go.id

Jabbarifar, T. (2009). The Importance Of Classroom Assessment And Evaluation In Educational System. InProceedings of the 2nd International Conference of Teaching and Learning (pp. 1-9). Malaysia: INTI University College.

Pantiwati, Y. (2011). Integrasi Asesmen Autentik dalam Pembelajaran. Jurnal Pengukuran Dan Penilaian., 11(2), $77-84$

Saptono, S., Rustaman, N. Y., -, S., \& Widodo, A. (2013). Model Integrasi Atribut Asesmen Formatif(Iaaf) Dalam Pembelajaran Biologi Sel Untuk Mengembangkan Kemampuan Penalaran Dan Berpikir Analitik Mahasiswa Calon Guru. Jurnal Pendidikan IPA Indonesia, 2(1), 31 - 40. https://doi.org/10.15294/jpii. v2i1.2507

Sholahuddin, A., \& Suharto, B. (2016). Implementasi Self Assesment Question dan Optimalisasi Praktikum pada Perkuliahan Dasar-dasar Pemisahan Analitik. Jurnal Ilmu Pendidikan, 15(1), 43-47. https://doi. org/10.17977/JIP.V15I1.10

Sihaloho, F. A. S. (2017). Hubungan Kemampuan Berpikir Kritis Dan Soft Skills Dengan Prestasi Belajar Siswa Pada Mata Pelajaran Ekonomi Kelas XI SMAN 1 LABUHAN DELI T.P 2015/2016. Prosiding Seminar Pendidikan Ekonomi Dan Bisnis, 3(1), 78 - 89.

Stears, M., \& Gopal, N. (2010). Exploring alternative assessment strategies in science classrooms. South African Journal of Education, 30(1), 591-604.

Sudjana, N. (2017). Penilaian hasil proses belajar mengajar. Bandung: PT Remaja Rosdakarya.

Sugiyono. (2016). Metode Penelitian Kuantitatif Kualitatif dan R\&amp;D. Bandung: Alfabeta.

Wiliam, D. (2013). Assessment: The Bridge between Teaching and Learning. Voices from the Middle, 21(2), 1520. Retrieved from www.readwritethink.org

Zaini, M. (2016). Guided Inquiry Based Learning on the Concept of Ecosystem Toward Learning Outcomes and Critical Thinking Skills of High School Students. IOSR Journal of Research \& Method in Education (IOSR-JRME), 6(6), 50-55. https://doi.org/10.9790/7388-0606085055 